ISSN: 2215-2644

revedu@gmail.com

Universidad de Costa Rica

Costa Rica

\title{
Evaluación psicométrica de la Escala de Procrastinación Académica (EPA) y la Escala de Resiliencia Académica (ARS-30) en personas universitarias de Quito- Ecuador
}

Zumárraga-Espinosa, Marcos; Cevallos-Pozo, Gabriela

Evaluación psicométrica de la Escala de Procrastinación Académica (EPA) y la Escala de Resiliencia Académica (ARS-30) en personas universitarias de Quito-Ecuador

Revista Educación, vol. 45, núm. 1, 2021

Universidad de Costa Rica, Costa Rica

Disponible en: http://www.redalyc.org/articulo.oa?id=44064134034

DOI: https://doi.org/10.15517/revedu.v45i1.42820

\section{(c) $\odot \Theta \Theta$}

Esta obra está bajo una Licencia Creative Commons Atribución-NoComercial-SinDerivar 3.0 Internacional. 


\title{
Evaluación psicométrica de la Escala de Procrastinación Académica (EPA) y la Escala de Resiliencia Académica (ARS-30) en personas universitarias de Quito-Ecuador
}

\author{
Psychometric Assessment of Academic Procrastination (APE) and Academic Resilience Scales (ARS-30) among \\ University Students in Quito, Ecuador
}

Marcos Zumárraga-Espinosa

Universidad Politécnica Salesiana, Ecuador

DOI: https://doi.org/10.15517/revedu.v45i1.42820

mzumarraga@ups.edu.ec

Redalyc: http://www.redalyc.org/articulo.oa?id=44064134034

(iD) https://orcid.org/0000-0001-9930-9005

Gabriela Cevallos-Pozo

Universidad Politécnica Salesiana, Ecuador

gcevallosp1@est.ups.edu.ec

(iD) https://orcid.org/0000-0002-3852-4091

Recepción: 22 Julio 2020

Aprobación: 06 Octubre 2020

\section{Resumen:}

Esta investigación instrumental tiene el objetivo de examinar las propiedades psicométricas de la Escala de Procrastinación Académica (EPA) y la Escala de Resiliencia Académica (ARS-30) en el contexto universitario ecuatoriano. Para ello se empleó una muestra de 788 estudiantes pertenecientes a universidades públicas y privadas del Distrito Metropolitano de Quito (DMQ). La recolección de los datos empleados en el estudio se realizó mediante cuestionarios escritos y auto-administrados. Para la evaluación de cada escala se compararon modelos de medición alternativos mediante el Análisis Factorial Confirmatorio. En cuanto a la EPA, se verifica que el mejor ajuste a los datos se alcanza a partir de una estructura bifactorial y el uso de una versión reducida del instrumento a 12 ítems $\left(\chi^{2}(53)=234.61[\mathrm{p}<.001]\right.$; GFI = .953; AGFI = .931; IFI = .930; CFI = .930; RMSEA = .066). Por otra parte, la ARS-30 exhibe una estructura trifactorial, con mayor calidad psicométrica de medición al emplearse una versión recortada a 24 ítems con re-especificación $\left(\chi^{2}(247)=951.98[\mathrm{p}<.001]\right.$; GFI $=.904 ;$ AGFI $=.884 ;$ IFI $=.904 ;$ CFI $=.903$; RMSEA $=.060$ ). Asimismo, las escalas ajustadas muestran resultados satisfactorios en términos de consistencia interna y validez nomológica. Se concluye que los instrumentos analizados, junto con las adaptaciones propuestas, cuentan con niveles aceptables de validez y confiabilidad para la medición/evaluación de la procrastinación y la resiliencia académica en el estudiantado universitario de Ecuador.

Palabras Clave: Psicometría, Procrastinación académica, Resiliencia académica, Universidad, Ecuador.

\section{Abstract:}

The psychometric properties of the Academic Procrastination (APS) and Academic Resilience Scales (ARS-30) were examined within an Ecuadorian university setting. The study sample included 788 students from both public and private universities in the Quito Metropolitan District (QMD). The study data was compiled from self-administered written questionnaires. Alternative measurement models were compared for each scale through Confirmatory Factor Analysis (CFA). The best data fit for the APS was attained from a bifactorial structure and the use of a reduced version of the assessment tool based on 12 items $\left(\chi^{2}(53)=234.61\right.$ $[\mathrm{p}<.001] ;$ GFI $=.953 ;$ AGFI $=.931 ; \mathrm{IFI}=.930 ; \mathrm{CFI}=.930 ; \mathrm{RMSEA}=.066)$. On the other hand, ARS-30 exhibits a trifactorial structure, with a higher psychometric measurement quality when using a 24-item cut version with re-specification $\left(\chi^{2}(247)=\right.$ $951.98[\mathrm{p}<.001]$; GFI $=.904 ; \mathrm{AGFI}=.884 ; \mathrm{IFI}=.904$; CFI $=.903$; RMSEA $=.060)$. The adjusted scales revealed satisfactory results in terms of internal consistency and nomological validity. The assessment tools and their proposed adaptations that were analyzed demonstrated acceptable levels of validity and reliability for measurement/ assessment of procrastination and academic resilience among Ecuador's university students.

Keywords: Psychometrics, Academic Procrastination, Academic Resilience, University, Ecuador. 


\section{1.- INTRODUCCIÓN}

Durante las últimas décadas, América Latina ha experimentado un importante incremento en el acceso a la educación superior, lo que ha resultado especialmente beneficioso para las y los estudiantes que provienen de los estratos socioeconómicos más bajos. Lastimosamente, hasta la actualidad, dicha masificación de la matricula no se ha acompañado de mejoras en los niveles de retención y graduación universitaria (Ferreyra, Avitabile, Botero-Álvarez, Haimovich-Paz y Urzúa, 2017). En términos comparativos, los niveles de fracaso y abandono estudiantil en la región siguen siendo bastante superiores a las cifras reportadas por los países más desarrollados (López-Segrera, 2016), siendo una problemática que, además, tiende a agudizarse en aquellas y aquellos estudiantes de menor nivel socioeconómico. Según datos del Banco Mundial, la tasa de finalización de estudios universitarios en la región presenta una importante brecha al comparar entre estudiantes del quintil de ingresos más alto y estudiantes que pertenecen a los dos quintiles más bajos, siendo el primer grupo el que cuenta con mayores probabilidades de graduación. Esta brecha oscila entre el 10\% y el 30\% en países como Colombia, Panamá, Brasil, Paraguay, Uruguay, Ecuador, Chile, Costa Rica y Argentina (Ferreyra, 2017). A modo general, las dificultades de adaptación e integración académica se sitúan entre las causas más relevantes del abandono universitario, dado que desembocan en situaciones de bajo rendimiento (Díaz-Peralta, 2008); cuestión que puede afectar con más intensidad a esta nueva población universitaria conformada por estudiantes de hogares con menores recursos, caracterizada, en gran medida, por acarrear una serie de desventajas académicas socialmente adquiridas, entre ellas: un limitado capital cognitivo, social y cultural; entornos familiares poco relacionados al ámbito universitario (estudiantes de primera generación universitaria); formación secundaria deficiente, entre otras (Guzmán-Valenzuela, 2017; Rama, 2009).

Dado este contexto regional, que no es ajeno al caso de la educación superior ecuatoriana (Bravo, Illescas, Larriva y Peña, 2017; Ponce y Carrasco, 2016), la formulación de estrategias tempranas centradas en prevenir el bajo rendimiento y el abandono universitario constituyen una necesidad fundamental para las instituciones de educación superior. Por lo tanto, se vuelve relevante la investigación centrada en los factores personales que favorecen los procesos de aprendizaje y la adaptación académica del estudiantado, por encima de variables de tipo cognitivo como los conocimientos y habilidades técnicas previamente adquiridas en la educación secundaria. Esto en vista de que, si bien las brechas académicas de partida en el ámbito universitario no siempre pueden evitarse (especialmente cuando se trata de establecimientos no selectivos), los factores no cognitivos pueden entrenarse satisfactoriamente con el fin de mejorar los resultados de aprendizaje de quienes experimenten una transición más problemática hacia la educación terciaria (Farrington et al., 2012). $\mathrm{Al}$ respecto, la evidencia meta-analítica apunta a que los factores no cognitivos, tales como características psicológicas (disposicionales, motivacionales, actitudinales) o habilidades autorregulatorias, desempeñan un rol explicativo predominante a la hora de dar cuenta del rendimiento académico en el ámbito universitario (Richardson, Abraham y Bond, 2012).

Paralelamente, la investigación de factores no cognitivos en la región demanda mayor trabajo metodológico, esto con el propósito de establecer instrumentos de medición rigurosamente validados, que aseguren criterios mínimos de calidad psicométrica (Munizaga, Cifuentes y Beltrán, 2018). Siguiendo a Allen, Robbins y Sawyer (2009), la efectividad de los programas de apoyo académico destinados a detectar e intervenir, desde un enfoque no cognitivo, a estudiantes en riesgo de fracaso y deserción, dependerá en gran medida de la calidad de las métricas empleadas para la valoración de las variables no cognitivas contempladas en los diagnósticos.

$\mathrm{Al}$ especificar las coordenadas analíticas, existen dos constructos no cognitivos relacionados con el desempeño universitario que han adquirido especial relevancia en el debate académico actual: la resiliencia académica y la procrastinación académica. Si bien el estudio de estas variables en Latinoamérica describe una trayectoria creciente (Caldera-Montes, Aceves-Lupercio y Reynoso-González, 2016; Garzón-Umerenkova y Gil-Flores, 2017a, 2017b; Peralta-Díaz, Ramírez-Giraldo y Castaño-Buitrago, 2011; Álvarez-Ramírez y 
Cáceres-Hernández, 2010), se requieren mayores esfuerzos metodológicos, con el objetivo de examinar la calidad psicométrica de los instrumentos a emplearse, a fin de determinar potencialidades de adaptación entre contextos nacionales y lograr consensos en cuanto a las formas de medición, que posibiliten una mayor comparabilidad internacional de resultados de investigación. En este sentido, el presente trabajo tiene por objetivo evaluar las propiedades psicométricas de la Escala de Procrastinación Académica (EPA) y la Escala de Resiliencia Académica (ARS-30) para el entorno universitario ecuatoriano, para contribuir metodológicamente a la exploración y estudio de estos constructos en dicho país.

La estructura del presente trabajo se detalla a continuación. Primero, se efectúa una revisión de la literatura en torno a los constructos de interés: procrastinación y resiliencia académica, a través del abordaje de aspectos como su conceptualización, relaciones relevantes y el estado metodológico de su medición en el contexto de América Latina. Segundo, se detalla la metodología de investigación empleada, así como las características de los instrumentos sometidos a evaluación. Tercero, en la sección de resultados, se examinan las propiedades psicométricas de la EPA y la ARS-30 en términos de validez factorial, confiabilidad y validez nomológica. Cuarto, se discuten los resultados obtenidos y se establecen conclusiones.

\section{2.- Revisión DE LITERATURA}

\section{Procrastinación académica}

La procrastinación académica se concibe como un efecto negativo de la mala administración del tiempo y la falta de autorregulación presentes en el estudiantado universitario en relación con aquellas tareas que resultan aversivas (Domínguez-Lara, 2017). Esta aparece cuando las personas estudiantes deciden aplazar el inicio de una actividad académica (tareas, lecturas, trabajos, preparación para exámenes, etc.) para completarla en el último momento, o bien, cuando excede los límites temporales establecidos para su realización; incluso pueden llegar hasta evitarla de manera indefinida (Álvarez-Ramírez y Cáceres-Hernández, 2010; Steel y Klingsieck, 2016).

Este fenómeno ha sido ampliamente relacionado con el rendimiento académico, pues se ha demostrado en la literatura que la población estudiantil que retrasa el estudio para los exámenes, que dedica menos horas de las necesarias a tareas y trabajos pendientes, que prioriza actividades sociales o recreativas sobre las académicas, tiende a tener un bajo rendimiento (Bravo et al., 2017). Asimismo, la asociación negativa entre procrastinación y rendimiento académico ha podido verificarse a nivel meta-analítico gracias a la investigación de Kim y Seo (2015). Adicional a esto, la procrastinación académica juega un papel decisivo en la deserción universitaria; según Garzón-Umerenkova y Gil-Flores (2017a), se trata de una variable que, desde el enfoque de las teorías del aprendizaje autorregulado, resulta ser un fuerte predictor del éxito o fracaso estudiantil.

Medición de la procrastinación académica: En la región latinoamericana, la Escala de Procrastinación Académica (EPA), desarrollada originalmente por Busko (1998), es quizá el instrumento que ha experimentado más procesos de evaluación psicométrica con relación al estudiantado universitario. A partir de la traducción y adaptación efectuada por Álvarez (2010), los trabajos de validación de la EPA abarcan países como Perú (Alegre, 2013; Domínguez-Lara, Villegas-García y Centeno-Leyva, 2014; Arias-Gallegos y Rivera, 2018) y México (Barraza-Macías y Barraza-Nevárez, 2018). En Ecuador, la EPA cuenta con un esfuerzo previo de validación a partir de una muestra de estudiantes en grado universitario de la ciudad de Ambato (Moreta-Herrera y Durán-Rodríguez, 2018). Dado este antecedente, y la amplitud evidenciada en el uso de la EPA a nivel regional, se eligió abordar este instrumento en la presente investigación con el objetivo de contrastar los hallazgos psicométricos realizados previamente en el contexto ecuatoriano, además 
de proporcionar nueva evidencia que pueda contribuir al debate metodológico en torno a la medición de la procrastinación académica en América Latina.

\section{Resiliencia académica}

Desde la década de los ochenta emergió una tendencia ascendente por conocer el fenómeno que permitía a un grupo de personas afrontar condiciones de vida adversas, superarlas y, además, transformarlas en ventajas o en impulso para lograr un mejor desarrollo biopsicosocial (Corchado-Castillo, Díaz-Aguado y MartínezArias, 2017). Es así como surge el constructo resiliencia, conocido como el resultado exitoso de adaptación a un entorno amenazante, que a la vez permite a la persona dar una respuesta saludable ante la exposición a condiciones desfavorables o de alto riesgo, superarlas y salir transformada positivamente por ellas (Cassidy, 2016; Vizoso-Gómez y Arias-Gundín, 2018).

En el ámbito académico, resulta de especial importancia comprender las razones que explican el hecho de que existan estudiantes capaces de finalizar sus estudios de manera exitosa, aun cuando el entorno educativo se torna adverso y hostil, mientras que otras personas sometidas a condiciones similares no lo consiguen (Martin, 2002). Una de las principales respuestas ha recaído en la resiliencia académica, considerada como la capacidad del estudiantado para generar respuestas adaptativas positivas frente a las adversidades, presiones y dificultades académicas para superarlas satisfactoriamente (Cassidy, 2016; Caldera-Montes et al., 2016). Además, se trata de un constructo que adquiere centralidad en el ámbito universitario que, dado su nivel de exigencia, implica una mayor exposición a tensiones y eventos estresantes (González-Torres y Artuch-Garde, 2017).

En este sentido, la literatura plantea una relación positiva entre la resiliencia y el rendimiento académico, pues se ha evidenciado que la población estudiantil que tiende a desempeñarse mejor académicamente se caracterizan por poseer iniciativa para completar tareas difíciles, asumir retos y percibir al fracaso como una oportunidad de reforzar los esfuerzos invertidos; todos estos son elementos implicados en la resiliencia (Alonso-Aldana, Beltrán-Márquez, Máfara-Duarte y Gaytán-Martínez, 2016; Peralta-Díaz et al., 2011). Además, aparte de elevar el rendimiento académico, reduciría las probabilidades de abandonar los estudios universitarios (Bethencourt-Benítez, Cabrera-Pérez, Hernández-Cabrera, Álvarez-Pérez y González-Afonso, 2017; Álvarez-Ramírez y Cáceres-Hernández, 2010).

Medición de la resiliencia: Si bien la resiliencia académica se ha convertido en un constructo de creciente interés en los últimos años, sus alternativas de medición resultan bastante escasas para el contexto universitario regional. Aparte de los desarrollos instrumentales centrados en los factores de protección que favorecen el comportamiento resiliente estudiantil (Peralta-Díaz et al., 2006), no se dispone de métricas debidamente validadas que se enfoquen de forma concreta en las respuestas generadas por cada estudiante ante eventos académicos adversos o estresantes, cuestión que, según la literatura especializada, es crucial para una medición adecuada de la resiliencia académica (Friedland, 2005). Ante esto, la Escala de Resiliencia Académica (ARS-30) propuesta por Cassidy (2016) constituye una alternativa que mide la capacidad adaptativa y de recuperación desde una perspectiva reacción-adversidad. En consecuencia, este trabajo se enfocará en la evaluación psicométrica de la ARS-30, con el fin de aportar información sobre la aplicabilidad de este instrumento en el caso ecuatoriano, además de favorecer la disponibilidad, en cuanto a la región, de alternativas de medición para la resiliencia académica en la universidad. 


\section{3.- MÉtodo}

\section{Diseño, participantes y procedimiento}

El presente estudio se enmarca en la categoría de investigación instrumental, la cual abarca aquellos trabajos encaminados al desarrollo de pruebas y aparatos, tanto en su diseño como adaptación, y al análisis de las propiedades psicométricas de instrumentos de medida psicológica (Ato, López-García y Benavente, 2013). En cuanto al tipo de información utilizada, se recolectaron datos de carácter transversal.

Para la evaluación psicométrica de las escalas de procrastinación y resiliencia académicas se empleó una muestra de 788 estudiantes de nivel universitario en Distrito Metropolitano de Quito (DMQ). Las personas participantes del estudio se seleccionaron de forma no probabilística, se introdujeron cuotas por sexo y tipo de universidad (pública/privada). La muestra contó con 389 (49.4\%) varones y 399 (50.6\%) mujeres. El 56.3\% de las y los estudiantes consultados pertenece a establecimientos públicos y el restante $43.7 \%$ a universidades privadas. La edad promedio se situó en 21.1 años $(\mathrm{DT}=2.77)$.

Los instrumentos se aplicaron con la ayuda de estudiantes de la carrera de Psicología de la Universidad Politécnica Salesiana (Sede Quito, Ecuador). El proceso de reclutamiento se llevó a cabo por conveniencia, tomando como criterio de inclusión que las personas participantes se encontraran formalmente matriculadas en un programa de estudios de tercer nivel al momento de efectuarse el estudio, respetándose las cuotas fijadas inicialmente. En cuanto a las consideraciones éticas, previo al llenado auto-diligenciado de los cuestionarios escritos, las personas participantes consintieron colaborar en la investigación de manera voluntaria, siendo debidamente informadas sobre los objetivos del estudio y los respectivos protocolos de confidencialidad para la protección de sus derechos e información personal. El levantamiento de datos tuvo lugar durante junio y julio de 2019.

Escala de Procrastinación Académica (EPA) : Este instrumento fue desarrollado originalmente por Busko (1998). No obstante, el proceso de validación se basó en la versión traducida y adaptada por Álvarez (2010) para el contexto peruano. La EPA está compuesta por 16 ítems que miden, desde una perspectiva conductual, la tendencia a procrastinar tareas y actividades en el plano académico. Cada ítem cuenta con las siguientes opciones de respuesta: 1 (Nunca), 2 (Pocas veces), 3 (A veces), 4 (Casi siempre), 5 (Siempre). En el caso de ítems formulados en sentido opuesto, la escala de valoración se invierte de manera que los puntajes altos indiquen un mayor grado de procrastinación en todos los casos.

Escala de Resiliencia Académica (ARS-30) : Esta escala, desarrollada por Cassidy (2016), constituye una alternativa para la medición de la resiliencia académica como un proceso. Para ello cuenta con dos componentes fundamentales: a) una adversidad académica hipotética y b) la cuantificación de respuestas adaptativas o no adaptativas de tipo cognitivo, afectivo y conductual. Así, en un primer momento, se le presenta al estudiante o la estudiante una situación adversa específica, propia de la vida universitaria, y se le solicita que se imagine como alguien experimentándola. La viñeta que representa tal experiencia estresante es: Usted ha recibido su calificación por una tarea reciente y es un fracaso. Las calificaciones de otras dos evaluaciones recientes también estuvieron por debajo de lo que usted desearia, tomando en cuenta que su objetivo es lograr el mejor promedio académico posible, puesto que tiene metas profesionales claras y no quiere decepcionar a su familia. Los comentarios de su profesor con respecto a la tarea entregada son bastante criticos, incluyendo problemas como 
falta de comprensión o escritura y expresión deficientes, aunque también incluye formas de mejorar el trabajo. Comentarios similares se hicieron por las y los profesores que calificaron las otras dos evaluaciones.

Ante la situación expuesta, se enlista un conjunto de 30 ítems que describen acciones de respuesta, entre adaptativas y no adaptativas, que podrían ser adoptadas. En este punto, el o la estudiante universitaria debe indicar cuán probable le resultaría reaccionar de cada una de las 30 formas contempladas. Así, la capacidad de recuperación se mide en función del grado de inclinación hacia comportamientos adaptativos y evitación de prácticas no adaptativas. Cada ítem cuenta con la siguiente escala de valoración: 1 (Nada probable), 2 (Poco probable), 3 (Algo probable), 4 (Muy probable), 5 (Totalmente probable). Sin embargo, en el caso de ítems formulados en sentido negativo, la escala de valoración se invierte con el fin de conservar la relación entre puntajes altos y mayor nivel de resiliencia académica. Para la traducción del instrumento ARS-30 se respetaron las recomendaciones de la literatura en lo tocante a equivalencia semántica, idiomática y conceptual, llevando a cabo un proceso de traducción-retraducción que posibilite mejorar la adaptación cultural de los ítems al contexto ecuatoriano (Ramada-Rodilla, Serra-Pujadas y Delclós-Clanchet, 2013).

Escala de Autoeficacia General (EAG): Desarrollada por Alegre (2013), consta de 20 ítems tipo Likert con opciones de respuesta que van desde 1 (Totalmente en desacuerdo) hasta 5 (Totalmente de acuerdo). El índice de autoeficacia general se obtiene sumando los puntajes-ítem de la escala, con un rango teórico de 20 a $100(M=77.66 ; D T=11.98 ; \alpha=.95)$.

\section{Análisis de datos}

Para evaluar la validez factorial de la EPA y la ARS-30 se empleó Análisis Factorial Confirmatorio (AFC). El análisis de confiabilidad se realizó a través del coeficiente Alfa de Cronbach $(\alpha)$. Los análisis fueron efectuados mediante los paquetes estadísticos SPSS 23 y AMOS 23. Finalmente, en todos los casos el AFC se realizó por máxima verosimilitud, puesto que tanto en la EPA como la ARS-30 pudo verificarse normalidad multivariante mediante el coeficiente de kurtosis multivariante de Mardia, que permitieron obtener valores satisfactorios por debajo del criterio $p(p+2)$, donde $\mathrm{p}$ corresponde al número de ítems por instrumento (Bollen, 1989). Además, para asegurar mayor confiabilidad y precisión de los resultados, la estimación de parámetros incorporó procedimientos de remuestreo/bootstrap (Byrne, 2010).

\section{4.- Resultados}

\section{Escala de Procrastinación Académica (EPA)}

La Tabla 1 muestra las medidas descriptivas de todos los ítems que integran originalmente la EPA. La investigación previa a nivel regional propone un modelo de medición caracterizado por reducir la EPA a 12 ítems y considerar a la procrastinación académica como un constructo bidimensional (Domínguez-Lara et al., 2014; Moreta-Herrera y Durán-Rodríguez, 2018). Es recurrente la identificación de las siguientes dimensiones correlacionadas: autorregulación académica (ítems: 2, 5, 6, 7, 10,11,12,13,14) y postergación de actividades (ítems: 1, 8,9), se destacan los ítems 3, 4, 15, 16. Con el propósito de verificar la validez factorial del modelo señalado (M1) para el caso ecuatoriano, se procedió a compararlo contra otras dos alternativas mediante AFC. El primer modelo competidor corresponde a la solución unifactorial planteada por Álvarez (2010) en su adaptación de la EPA al español, con una estructura original de 16 ítems (M2). Asimismo, dada la existencia de posturas que abogan por la procrastinación académica como un concepto unidimensional (Arias-Gallegos y Rivera, 2018), el segundo modelo competidor explora la posibilidad de que la EPA recortada capture información de un mismo constructo (M3). 
TABLA 1

Descriptivos por ítem: Escala de Procrastinación Académica (EPA)

\begin{tabular}{l|llll}
\hline Ítems/EPA & M & DT & Asimetría & Curtosis \\
\hline $\begin{array}{l}\text { 1.- Cuando tengo que hacer una tarea, normalmente la } \\
\text { dejo para el último minuto }\end{array}$ & 2.69 & .99 & .17 & -.25 \\
\hline $\begin{array}{l}\text { 2.- Generalmente me preparo por adelantado para los } \\
\text { exámenes }\end{array}$ & 2.92 & .98 & -.05 & -.52 \\
\hline $\begin{array}{l}\text { 3.- Cuando me asignan lecturas, las leo la noche } \\
\text { anterior }\end{array}$ & 2.99 & 1.07 & -.01 & -.58 \\
\hline $\begin{array}{l}\text { 4.- Cuando me asignan lecturas, las reviso el mismo } \\
\text { día de la clase }\end{array}$ & 3.27 & 1.09 & -.21 & -.55 \\
\hline $\begin{array}{l}\text { 5.- Cuando tengo problemas para entender algo, } \\
\text { inmediatamente trato de buscar ayuda }\end{array}$ & 2.38 & 1.02 & .42 & -.42 \\
\hline $\begin{array}{l}\text { 6.- Asisto regularmente a clases } \\
\text { 7.- Trato de completar el trabajo asignado lo más } \\
\text { pronto posible }\end{array}$ & 2.62 & .93 & 1.69 & 2.58 \\
\hline $\begin{array}{l}\text { 8.- Postergo los trabajos de los cursos que no me } \\
\text { gustan }\end{array}$ & 2.80 & 1.08 & .53 & -.35 \\
\hline $\begin{array}{l}\text { 9.- Postergo las lecturas de los cursos que no me } \\
\text { gustan }\end{array}$ & 2.80 & 1.09 & .10 & -.54 \\
\hline $\begin{array}{l}\text { 10.- Constantemente intento mejorar mis hábitos de } \\
\text { estudio }\end{array}$ & 2.42 & .95 & .40 & -.60 \\
\hline $\begin{array}{l}\text { 11.- Invierto el tiempo necesario en estudiar aun } \\
\text { cuando el tema sea aburrido }\end{array}$ & 2.73 & 1.00 & .03 & -.52 \\
\hline $\begin{array}{l}\text { 12.- Trato de motivarme para mantener mi ritmo de } \\
\text { estudio }\end{array}$ & 2.35 & .99 & .43 & -.33 \\
\hline $\begin{array}{l}\text { 13.- Trato de terminar mis trabajos importantes con } \\
\text { tiempo de sobra }\end{array}$ & 2.49 & .98 & .15 & -.61 \\
\hline $\begin{array}{l}\text { 14.- Me tomo el tiempo de revisar mis tareas antes de } \\
\text { entregarlas }\end{array}$ & 2.40 & 1.11 & .38 & -.69 \\
\hline $\begin{array}{l}\text { 15.- Raramente dejo para mañana lo que puedo hacer } \\
\text { hoy }\end{array}$ & 3.02 & .97 & -.16 & -.24 \\
\hline $\begin{array}{l}\text { 16.- Disfruto la mezcla de desafío con emoción de } \\
\text { ssperar hasta el último minuto para completar una } \\
\text { tarea }\end{array}$ & 2.62 & 1.24 & .32 & -.86 \\
\hline
\end{tabular}

Fuente: Elaboración propia con base en encuestas aplicadas a estudiantes de universidades públicas y privadas del DMQ (Ecuador), Junio-Julio, 2019.

El examen de la adecuación de cada modelo a los datos se efectuó a partir del uso de los siguientes indicadores de bondad de ajuste: índice de bondad de ajuste (GFI); índice ajustado de bondad de ajuste (AGFI), índice de ajuste incremental (IFI), índice de ajuste comparativo (CFI) y raíz del residuo cuadrático promedio de aproximación (RMSEA). Los criterios de referencia que denotan un ajuste aceptable son: GFI, IFI, CFI $\geq 0.90 ;$ AGFI $\geq 0.85$; RMSEA $\leq 0.08$ (Schermelleh-Engel, Moosbrugger y Müller, 2003). También se reportan los resultados de la prueba chi-cuadrado $\left(\chi^{2}\right)$, no obstante, puesto que evalúa la presencia de un ajuste exacto, se torna complicado confirmar tal hipótesis incluso en modelos que poseen un buen ajuste, especialmente cuando $n>200$ (Zumárraga-Espinosa, 2020). Por esta razón, dicha prueba se reporta únicamente a modo informativo. Para la comparación entre modelos se optó por el criterio de información de Akaike (AIC) y su versión consistente (CAIC), los cuales permiten contrastar diferentes modelos no anidados en razón de su calidad de aproximación a la realidad, teniendo un mejor ajuste aquel modelo con valores más bajos para estos indicadores (Byrne, 2010; Werner y Schermelleh-Engel, 2010).

La Tabla 2 presenta los resultados del AFC. Como puede observarse, M1 constituye la única solución factorial que logra un ajuste satisfactorio respecto a los datos observados, según los indicadores y criterios contemplados. Esto se corrobora al evaluar los índices AIC y CAIC, siendo M1 el modelo que adopta valores más bajos. En consecuencia, la comparación de modelos realizada permite confirmar que el modelo 
de medición, basado en la versión recortada de la EPA y una estructura bidimensional, cuenta con validez factorial para el caso ecuatoriano, además de ser la mejor opción en términos de bondad de ajuste.

TABLA 2

Análisis factorial confirmatorio modelos alternativos de medición a partir de la EPA

\begin{tabular}{|l|l|l|l|l|l|l|l|l|l|l|}
\hline Modelos & $\mathrm{x}^{2}$ & $\mathrm{gl}$ & $\mathrm{p}$-valor & GFI & AGFI & IFI & CFI & RMSEA & AIC & CAIC \\
\hline M1: EPA recortada bifactorial & 234.61 & 53 & $<.001$ & .953 & .931 & .930 & .930 & .066 & 284.61 & 426.35 \\
\hline M2: EPA recortada unifactorial & 724.69 & 54 & $<.001$ & .884 & .832 & .742 & .741 & 126 & 772.69 & 908.76 \\
\hline M3: EPA original unifactorial & 967.12 & 104 & $<.001$ & .867 & .826 & .697 & .695 & .103 & 1031.12 & 1212.55 \\
\hline
\end{tabular}

Fuente: Elaboración propia con base en encuestas aplicadas a estudiantes de universidades públicas y privadas del DMQ (Ecuador), Junio-Julio, 2019.

Complementariamente, la Tabla 3 muestra la correlación entre factores y las cargas factoriales correspondientes a M1. Las estimaciones se desarrollaron mediante un procedimiento de remuestreo basado en 2000 submuestras con reemplazamiento; además, se construyen intervalos de confianza de sesgo-corregido al 95\%. Los resultados indican que, salvo por el ítem 1 (que se acerca mucho); todas las cargas factoriales tienen valores por encima de 0.30 , considerando el límite inferior de los intervalos de confianza, lo que concuerda con lo recomendado por la literatura especializada (Field, 2013). Todos los ítems operan como indicadores significativos de sus respectivos factores $(\mathrm{p}<0.01)$. 
TABLA 3

EPA/M1: Cargas factoriales y correlación interfactorial

\begin{tabular}{|c|c|c|c|c|}
\hline & F1 & & $\mathrm{F} 2$ & \\
\hline $\begin{array}{l}\text { Dimensiones/Procrastinación } \\
\text { académica }\end{array}$ & Carga factorial & IC $95 \%$ & Carga factorial & IC $95 \%$ \\
\hline \multicolumn{5}{|l|}{$\begin{array}{l}\text { Factor 1: Autorregulación } \\
\text { académica }\end{array}$} \\
\hline $\begin{array}{l}\text { 2.- Generalmente me preparo } \\
\text { por adelantado para los } \\
\text { exámenes }\end{array}$ & .42 & $.35-.49$ & & \\
\hline $\begin{array}{l}\text { 5.- Cuando tengo problemas } \\
\text { para entender algo, } \\
\text { inmediatamente trato de buscar } \\
\text { ayuda }\end{array}$ & .50 & $.43-.57$ & & \\
\hline 6.- Asisto regularmente a clases & .51 & $.42-.58$ & & \\
\hline $\begin{array}{l}\text { 7.- Trato de completar el trabajo } \\
\text { asignado lo más pronto posible }\end{array}$ & .60 & $.53-.66$ & & \\
\hline $\begin{array}{l}\text { 10.- Constantemente intento } \\
\text { mejorar mis hábitos de estudio }\end{array}$ & .67 & $.61-.73$ & & \\
\hline $\begin{array}{l}\text { 11. - Invierto el tiempo necesario } \\
\text { en estudiar aun cuando el tema } \\
\text { sea aburrido }\end{array}$ & .59 & $.53-.64$ & & \\
\hline $\begin{array}{l}\text { 12.- Trato de motiv arme para } \\
\text { mantener mi ritmo de estudio }\end{array}$ & .73 & $.69-.77$ & & \\
\hline $\begin{array}{l}\text { 13.- Trato de terminar mis } \\
\text { trabajos importantes con tiempo } \\
\text { de sobra }\end{array}$ & .68 & $.63-.73$ & & \\
\hline $\begin{array}{l}\text { 14.- Me tomo el tiempo de } \\
\text { revisar mis tareas antes de } \\
\text { entregarlas }\end{array}$ & .60 & $.54-.66$ & & \\
\hline \multicolumn{5}{|l|}{$\begin{array}{l}\text { Factor 2: Postergación de } \\
\text { actividades }\end{array}$} \\
\hline $\begin{array}{l}\text { 1.- Cuando tengo que hacer una } \\
\text { tarea, normalmente la dejo para } \\
\text { el último minuto }\end{array}$ & & & .35 & $.27-.43$ \\
\hline $\begin{array}{l}\text { 8.- Postergo los trabajos de los } \\
\text { cursos que no me gustan }\end{array}$ & & & .86 & $.78-.93$ \\
\hline $\begin{array}{l}\text { 9.- Postergo las lecturas de los } \\
\text { cursos que no me gustan }\end{array}$ & & & .82 & $.75-.88$ \\
\hline Correlación entre F1 y F2 & \multicolumn{4}{|c|}{$r=.26 ; \mathrm{IC} 95 \%[.17-.36]$} \\
\hline
\end{tabular}

Fuente: Elaboración propia con base en encuestas aplicadas a estudiantes de universidades públicas y privadas del DMQ (Ecuador), Junio-Julio, 2019.

El análisis de confiabilidad de M1 se expone en la Tabla 4. Si bien la subescala postergación de actividades $(\alpha=.693)$ se encuentra apenas por debajo del criterio recomendado de 0.70 , tanto la subescala autorregulación académica $(\alpha=.826)$ como el instrumento considerado de forma global $(\alpha=.814)$ reportan niveles satisfactorios de consistencia interna.

TABLA 4

Análisis de confiabilidad: M1/EPA

\begin{tabular}{ll}
\hline & $\alpha$ de Cronbach \\
\hline $\begin{array}{l}\text { Subescala: Autorregulación } \\
\text { académica (9 ítems) }\end{array}$ & .826 \\
\hline $\begin{array}{l}\text { Subescala: Postergación de } \\
\text { actividades (3 items) }\end{array}$ & .693 \\
\hline Escala Global (12 ítems) & .814 \\
\hline
\end{tabular}


Fuente: Elaboración propia con base en encuestas aplicadas a estudiantes de universidades públicas y privadas del DMQ (Ecuador), Junio-Julio, 2019.

\section{Escala de Resiliencia Académica (ARS-30)}

Al ser una escala de reciente creación (2016), la ARS-30 no cuenta aún con antecedentes exhaustivos de validación para el caso latinoamericano. Por esta razón, se tomó como punto de partida el modelo de medición propuesto por Cassidy (2016), con base en su revisión psicométrica inicial. Según dicho modelo, las respuestas adaptativas-no adaptativas que el estudiantado universitario puede desarrollar frente a adversidades académicas se agrupan en tres dimensiones: a) perseverancia (ítems: $1,2,3,4,5,8,9,10$, $11,13,15,16,17,30$ ); b) reflexión y búsqueda adaptativa de ayuda (ítems: 18, 20, 21, 22, 24, 25, 26, 27 , 29); y c) afectación negativa y respuesta emocional (ítems: 6, 7, 12, 14, 19, 23, 28). En un primer momento, esta estructura factorial se evaluó en términos de bondad de ajuste vía AFC. Posteriormente se procedió a descartar aquellos ítems con desempeño psicométrico deficiente, contemplándose como criterio de decisión la magnitud de las cargas factoriales analizadas a partir de los respectivos intervalos de confianza. Por último, se introduce una ligera re-especificación del modelo recortado mediante la correlación entre errores de medición. La Tabla 5 muestra las medidas descriptivas del conjunto de ítems de la ARS-30. El AFC de cada modelo se efectuó siguiendo los mismos protocolos establecidos inicialmente para las pruebas factoriales de la EPA. 
TABLA 5

Descriptivos por ítem: Escala de Resiliencia Académica (ARS-30)

\begin{tabular}{|c|c|c|c|c|}
\hline Ítems / ARS-30 & $\mathrm{M}$ & DT & Asimetría & Curtosis \\
\hline $\begin{array}{l}\text { 1.- No aceptaría la retroalimentación } \\
\text { de los profesores }\end{array}$ & 3.71 & 1.17 & -.58 & -.62 \\
\hline $\begin{array}{l}\text { 2.- Usaría la retroalimentación para } \\
\text { mejorar mi trabajo }\end{array}$ & 3.92 & 1.01 & -.84 & .19 \\
\hline 3.- Solo me rendiría & 4.29 & .98 & -1.35 & 1.20 \\
\hline $\begin{array}{l}\text { 4.- Usaría la situación para } \\
\text { motivarme a mí mismo }\end{array}$ & 3.74 & 1.03 & -.61 & -.17 \\
\hline 5.- Cambiaría mis planes de carrera & 4.02 & 1.09 & -.93 & -.04 \\
\hline 6.- Probablemente de molestaría & 3.30 & 1.12 & -.21 & -.63 \\
\hline $\begin{array}{l}\text { 7.- Empezaría a pensar que mis } \\
\text { posibilidades de éxito en la } \\
\text { universidad eran pobres }\end{array}$ & 3.88 & 1.06 & -.74 & -.17 \\
\hline $\begin{array}{l}\text { 8.- Vería la situación como un } \\
\text { desafío }\end{array}$ & 3.39 & 1.06 & -.29 & -.54 \\
\hline $\begin{array}{l}\text { 9.- Haría todo lo posible para detener } \\
\text { pensamientos negativos }\end{array}$ & 3.38 & 1.15 & -.38 & -.67 \\
\hline 10.- Vería la situación como temporal & 3.41 & 1.03 & -.35 & -.35 \\
\hline 11.- Trabajaría más duro & 3.93 & 1.03 & -.85 & .14 \\
\hline 12.- Probablemente me deprimiría & 3.43 & 1.20 & -.38 & -.80 \\
\hline $\begin{array}{l}\text { 13.- Trataría de pensar en nuevas } \\
\text { soluciones }\end{array}$ & 3.71 & 1.02 & -.70 & .05 \\
\hline 14.- Estaría muy decepcionado & 3.23 & 1.16 & -.21 & -.76 \\
\hline 15.- Culparía al profesor & 3.78 & 1.10 & -.75 & -.13 \\
\hline 16.- Seguiría intentando & 3.91 & 1.05 & -.91 & .23 \\
\hline $\begin{array}{l}\text { 17.- No cambi aría mis metas y } \\
\text { ambiciones a largo plazo }\end{array}$ & 3.61 & 1.26 & -.61 & -.68 \\
\hline $\begin{array}{l}\text { 18.- Usaría mis éxitos pasados para } \\
\text { que me ayuden a motivarme }\end{array}$ & 3.81 & 1.05 & -.67 & -.19 \\
\hline $\begin{array}{l}\text { 19.- Empezaría a pensar que mis } \\
\text { posibilidades de conseguir el trabajo } \\
\text { que quiero eran escasas }\end{array}$ & 3.55 & 1.26 & -.47 & -.88 \\
\hline $\begin{array}{l}\text { 20.- Empezaría a supervisar y evaluar } \\
\text { mis logros y esfuerzos }\end{array}$ & 3.53 & 1.01 & -.36 & -.35 \\
\hline $\begin{array}{l}\text { 21.- Buscaría ayuda de mis } \\
\text { profesores }\end{array}$ & 3.61 & 1.08 & -.54 & -.37 \\
\hline 22.- Me daría ánimos a mí mismo & 3.93 & .99 & -.67 & -.14 \\
\hline 23.- Trataría de no entrar en pánico & 3.61 & 1.06 & -.61 & -.18 \\
\hline $\begin{array}{l}\text { 24.- Intentaría diferentes formas de } \\
\text { estudiar }\end{array}$ & 3.74 & 1.02 & -.64 & -.04 \\
\hline $\begin{array}{l}\text { 25.- Definiría mis propias metas para } \\
\text { lograrlas }\end{array}$ & 3.82 & .99 & -.71 & .09 \\
\hline $\begin{array}{l}\text { 26.- Buscaría el apoyo de mi familia } \\
\text { y amigos }\end{array}$ & 3.62 & 1.10 & -.51 & -.49 \\
\hline $\begin{array}{l}\text { 27.- Trataría de pensar más en mis } \\
\text { fortalezas y debilidades para que me } \\
\text { ayude a trabajar mejor }\end{array}$ & 3.74 & 1.05 & -.68 & -.11 \\
\hline $\begin{array}{l}\text { 28.- Me sentiría como si todo } \\
\text { estuviera arruinado y estuviera } \\
\text { saliendo mal }\end{array}$ & 3.57 & 1.24 & -.49 & -.77 \\
\hline $\begin{array}{l}\text { 29.- Empezaría a imponerme } \\
\text { recompensas y castigos dependiendo } \\
\text { de mi rendimiento }\end{array}$ & 2.86 & 1.16 & .09 & -.83 \\
\hline $\begin{array}{l}\text { 30.- Miraría hacia adelante para } \\
\text { demostrar que puedo mejorar mis } \\
\text { calificaciones }\end{array}$ & 3.95 & .98 & -.83 & .30 \\
\hline
\end{tabular}

Fuente: Elaboración propia con base en encuestas aplicadas a estudiantes de universidades públicas y privadas del DMQ (Ecuador), Junio-Julio, 2019. 
En la Tabla 6 se presentan los resultados del AFC de cada modelo de medición revisado. Como puede observarse, el modelo factorial de carácter tridimensional (modelo 1), originalmente planteado por Cassidy (2016), no alcanza valores satisfactorios de bondad de ajuste. Dado que dicha estructura factorial es pertinente a nivel de contenido, además de poseer un fundamento teórico consistente. La ruta de validación elegida consistió en detectar aquellos ítems con cargas factoriales insuficientes $(<0.30)$, para lo cual, y en búsqueda de estimaciones más confiables, se consideró el límite inferior de los intervalos de confianza (IC 95\%) obtenidos por remuestreo. Así, se descartaron 6 ítems: 1, 5, 6, 15, 23 y 29. En consecuencia, la versión recortada de la ARS-30 (modelo 2) quedó conformada por 24 ítems distribuidos de la siguiente forma: perseverancia (11 ítems), reflexión y búsqueda adaptativa de ayuda (8 ítems), afectación negativa y respuesta emocional ( 5 ítems). Todos los indicadores de bondad de ajuste contemplados reportaron una mejoría considerable para la escala recortada. No obstante, la evaluación de los índices de modificación, proporcionados por AMOS 23, sugiere que el modelo 2 puede mejorarse aún más al incorporar covarianzas entre los errores de medición de los ítems: 9 y $10(\mathrm{r}=.28, \mathrm{p}<.01$, IC 95\% [.18 - .37]); 12 y $14(\mathrm{r}=.31, \mathrm{p}$ $<.01$, IC 95\% [.23 - .39]). Al efectuarse dicha re-especificación (modelo 3), la estructura factorial establecida (tres dimensiones intercorrelacionadas capturadas mediante 24 ítems) cumple con los criterios para un ajuste aceptable en todos los índices (ver Tabla 6).

TABLA 6

Análisis factorial confirmatorio: modelos alternativos de medición a partir de la ARS-30

\begin{tabular}{|l|l|l|l|l|l|l|l|l|l|l|}
\hline ModeloS & $\mathrm{X}^{2}$ & $\mathrm{gl}$ & $\mathrm{p}$-valor & GFI & AGFI & IFI & CFI & RMSEA & AIC & CAIC \\
\hline M1: ARS-30 original trifactorial & 2462.60 & 402 & $<.001$ & .806 & .775 & 769 & .768 & .081 & 2588.60 & 2945.78 \\
\hline M2: ARS-30 recortada trifactorial & 1067.68 & 249 & $<.001$ & .893 & 871 & 888 & 888 & .065 & 1169.68 & 1458.82 \\
\hline M3: ARS-30 recortada trifactorial con re-especificación & 951.98 & 247 & $<.001$ & .904 & .884 & .904 & .903 & .060 & 1057.98 & 1358.46 \\
\hline
\end{tabular}

Fuente: Elaboración propia con base en encuestas aplicadas a estudiantes de universidades públicas y privadas del DMQ (Ecuador), Junio-Julio, 2019.

Cabe resaltar que únicamente se correlacionaron errores entre ítems vinculados a nivel conceptual. Los ítems 9 (Haria todo lo posible para detener pensamientos negativos) y 10 (Vería la situación como temporal) se refieren a la evitación de una actitud catastrofista y la gestión optimista de los pensamientos que resultan de experimentar adversidades académicas. Mientras que los ítems 12 (Probablemente me deprimiría) y 14 (Estaria muy decepcionado) poseen un importante solapamiento de contenido. Esto vuelve razonable el que los errores correlacionados tengan consistencia más allá de los datos específicos aquí analizados, especialmente para el caso ecuatoriano. La Tabla 7 presenta las cargas factoriales y las correlaciones interfactoriales correspondientes al modelo 3. Siguiendo el procedimiento de remuestreo, todas las cargas factoriales superan el criterio de 0.30 (Field, 2013), tomando como referencia el límite inferior de los respetivos intervalos de confianza al $95 \%$. 
TABLA 7

ARS-30/M3: Cargas factoriales y correlaciones interfactoriales

\begin{tabular}{|c|c|c|c|c|c|}
\hline & F1 & & F2 & F3 & \\
\hline Dimensiones / Resiliencia académica & Carga factorial & IC $95 \%$ & Carga factorial IC 95\% & Carga factorial & IC $95 \%$ \\
\hline \multicolumn{6}{|l|}{ Factor 1: Perseverancia } \\
\hline $\begin{array}{l}\text { 2.- Usaría la retroalimentación para mejorar mi } \\
\text { trabajo }\end{array}$ & .61 & $.54-.67$ & & & \\
\hline 3.- Solo me rendiría & .43 & $.35-.50$ & & & \\
\hline $\begin{array}{l}\text { 4.- Usaría la situación para motivarme a mí } \\
\text { mismo }\end{array}$ & .60 & $.54-.66$ & & & \\
\hline 8.- Vería la situación como un desafío & .47 & $.40-.54$ & & & \\
\hline $\begin{array}{l}\text { 9.- Haría todo lo posible para detener } \\
\text { pensamientos negativos }\end{array}$ & .52 & $.44-.59$ & & & \\
\hline 10.- Vería la situación como temporal & .51 & $.44-.58$ & & & \\
\hline 11.- Trabajaría más duro & .73 & $.67-.78$ & & & \\
\hline 13.- Trataría de pensar en nuevas soluciones & .70 & $.64-.75$ & & & \\
\hline 16.- Seguiría intentando & .67 & $.61-.72$ & & & \\
\hline $\begin{array}{l}\text { 17.- No cambiaría mis metas y ambiciones a largo } \\
\text { plazo }\end{array}$ & .52 & $.45-.58$ & & & \\
\hline $\begin{array}{l}\text { 30.- Miraría hacia adelante para demostrar que } \\
\text { puedo mejorar mis calificaciones }\end{array}$ & .75 & $.70-.79$ & & & \\
\hline \multicolumn{6}{|l|}{$\begin{array}{l}\text { Factor 2: Reflexión y búsqueda adaptativa de } \\
\text { ayuda }\end{array}$} \\
\hline $\begin{array}{l}\text { 18.- Usaría mis éxitos pasados para que me } \\
\text { ayuden a motivarme }\end{array}$ & & & $.66-.76$ & & \\
\hline $\begin{array}{l}\text { 20.- Empezaría a supervisar y evaluar mis logros y } \\
\text { esfuerzos }\end{array}$ & & & $.55-.67$ & & \\
\hline 21.- Buscaría ayuda de mis profesores & & & $.56-.67$ & & \\
\hline 22.- Me daría ánimos a mí mismo & & & $.72-.80$ & & \\
\hline 24.- Intentaría diferentes formas de estudiar & & & $.71-.80$ & & \\
\hline 25.- Definiría mis propias metas para lograrlas & & & $.74-.82$ & & \\
\hline 26.- Buscaría el apoyo de mi familia y amigos & & & $.53-.66$ & & \\
\hline $\begin{array}{l}27 .- \text { Trataría de pensar más en mis fortalezas y } \\
\text { debilidades para que me ayude a trabajar mejor }\end{array}$ & & & $.61-.72$ & & \\
\hline \multicolumn{6}{|l|}{$\begin{array}{l}\text { Factor } 3: \text { Afectación negativa y respuesta } \\
\text { emocional }\end{array}$} \\
\hline $\begin{array}{l}\text { 7.- Empezaría a pensar que mis posibilidades de } \\
\text { éxito en la universidad eran pobres }\end{array}$ & & & & 62 & $.54-.70$ \\
\hline 12.- Probablemente me deprimiría & & & & .58 & $.50-.65$ \\
\hline 14.- Estaría muy decepcionado & & & & .43 & $.34-.52$ \\
\hline $\begin{array}{l}\text { 19.- Empezaría a pensar que mis posibilidades de } \\
\text { conseguir el trabajo que quiero eran escasas }\end{array}$ & & & & .57 & $.50-.64$ \\
\hline $\begin{array}{l}\text { 28. - Me sentiría como si todo estuviera arruinado } \\
\text { y estuviera saliendo mal }\end{array}$ & & & & 67 & $.59-.74$ \\
\hline Correlación F1 y F2 & \multicolumn{5}{|c|}{$r=.91 ; \mathrm{IC} 95 \%[.87-.94]$} \\
\hline Correlación F1 y F3 & \multicolumn{5}{|c|}{$r=.39 ; \mathrm{IC} 95 \%[.30-.49]$} \\
\hline Correlación F2 y F3 & \multicolumn{5}{|c|}{$\mathrm{r}=.25 ; \mathrm{IC} 95 \%[.14-.35]$} \\
\hline
\end{tabular}

Fuente: Elaboración propia con base en encuestas aplicadas a estudiantes de universidades públicas y privadas del DMQ (Ecuador), Junio-Julio, 2019.

La evaluación de confiabilidad indica que la ARS-30 reducida tiene un grado de consistencia interna satisfactorio $(\alpha=.90)$. Ocurre lo mismo a nivel de subescalas, con valores $\alpha$ que van desde .73 hasta .86 (véase Tabla 8). 
TABLA 8

Análisis de confiabilidad: M3/ARS-30

\begin{tabular}{ll}
\hline & $\alpha$ de Cronbach \\
\hline $\begin{array}{l}\text { Subescala: Perseverancia (11 ítems) } \\
\begin{array}{l}\text { Subescala: Reflexión y búsqueda } \\
\text { adaptativa de ayuda ( } 8 \text { ítems) }\end{array}\end{array}$ & .86 \\
\hline $\begin{array}{l}\text { Subescala: Afectación negativa y } \\
\text { respuesta emocional (5 ítems) }\end{array}$ & .73 \\
\hline Escala global (24 ítems) & .90 \\
\hline
\end{tabular}

Fuente: Elaboración propia con base en encuestas aplicadas a estudiantes de universidades públicas y privadas del DMQ (Ecuador), Junio-Julio, 2019.

Fuente: Elaboración propia con base en encuestas aplicadas a estudiantes de universidades públicas y privadas del DMQ (Ecuador), Junio-Julio, 2019.

\section{Validez nomológica: EPA / ARS -30}

Por validez nomológica, en su forma más simple, se entiende que, si dos constructos se encuentran vinculados a nivel teórico, entonces sus respectivas métricas, de ser correctas, deberían correlacionarse empíricamente (Hagger, Gucciardi y Chatzisarantis, 2017). En este sentido, la literatura posiciona al sentido de autoeficacia de las y los estudiantes universitarios como un constructo asociado tanto a la procrastinación como a la resiliencia académica (Alegre, 2013; Cassidy, 2015; Narayanan y Weng Onn, 2016; Van Eerde, 2003). Para este análisis se consideraron las versiones M1 (bifactorial, 12 ítems) de la PEA y M3 (trifactorial, 24 ítems, re-especificación respecto a correlación entre residuales) de la ARS-30, que son los modelos de medición que mostraron mejor desempeño psicométrico en el AFC.

El análisis correlacional (Tabla 9) revela que la autoeficacia se asocia de manera significativa y negativa con la procrastinación académica $(\mathrm{r}=-.34 ; \mathrm{p}<.01)$. Del mismo modo, se observan correlaciones significativas y con el mismo signo por cada dimensión de procrastinación, donde la autorregulación académica fue el componente más fuertemente asociado a la autoeficacia $(\mathrm{r}=-.35 ; \mathrm{p}<.01)$. En el caso de la resiliencia académica se encontró una relación significativa, positiva y moderada con la autoeficacia $(\mathrm{r}=.40 ; \mathrm{p}<.01)$. Las modalidades de la resiliencia mantienen este mismo patrón de asociación, salvo por el factor afectación negativa y respuesta emocional que presenta una relación más débil $(\mathrm{r}=.28 ; \mathrm{p}<.01)$. A modo general, las asociaciones observadas permiten verificar las expectativas teóricas en torno a los constructos de interés, que aportan evidencia de validez nomológica para sus respectivas métricas. 
TABLA 9

Análisis correlacional: EPA y ARS-30 vs Autoeficacia General

\begin{tabular}{|c|c|c|c|c|}
\hline & Rango teórico & $\mathrm{M}$ & DT & Autoeficacia general \\
\hline \multicolumn{5}{|l|}{$\begin{array}{l}\text { Escala de Procrastinación } \\
\text { Académica (EPA). Bifactorial } \\
\text { recortada }\end{array}$} \\
\hline $\begin{array}{l}\text { Autorregulación académica ( } 9 \\
\text { ítems) }\end{array}$ & $9-45$ & 21.48 & 5.80 & $-.35 * *$ \\
\hline $\begin{array}{l}\text { Postergación de actividades ( } 3 \\
\text { items) }\end{array}$ & $3-15$ & 8.30 & 2.50 & $-.15^{* *}$ \\
\hline Escala Global (12 ítems) & $12-60$ & 29.78 & 6.94 & $-.34 * *$ \\
\hline \multicolumn{5}{|l|}{$\begin{array}{l}\text { Escala de Resiliencia Académica } \\
\text { (ARS-30). Tres factores, } \\
\text { recortada y correlación de } \\
\text { residuales }\end{array}$} \\
\hline Perseverancia (11 ítems) & $11-55$ & 41.25 & 7.44 & $40^{* *}$ \\
\hline $\begin{array}{l}\text { Reflexión y búsqueda } \\
\text { adaptativa de ayuda ( } 8 \text { ítems) }\end{array}$ & $8-40$ & 29.79 & 6.10 & $.41 * *$ \\
\hline $\begin{array}{l}\text { Afectación negativa y respuesta } \\
\text { emocional (5 items) }\end{array}$ & $5-25$ & 17.66 & 4.13 & $.28^{* *}$ \\
\hline Escala Global (24 ítems) & $24-120$ & 88.70 & 14.25 & $.46^{* *}$ \\
\hline
\end{tabular}

Fuente: Encuestas aplicadas a estudiantes de universidades públicas y privadas del DMQ (Ecuador), Junio-Julio, 2019. Elaboración propia Nota: ${ }^{* *} \mathrm{p}<0.01$

Nota: ${ }^{* *} \mathrm{p}<0.01$

Finalmente, la verificación de una medición multidimensional tanto para la EPA (M1) como la ARS-30 (M3), a través del AFC, apunta a que los ítems agrupados en una dimensión específica se intercorrelacionan más entre sí, que con respecto a los ítems de otras subescalas. Lo cual aporta evidencia de validez convergente y discriminante a favor de los instrumentos evaluados (Batista-Foguet, Coenders y Alonso, 2004).

\section{5.- Conclusiones}

La presente investigación instrumental se propuso contribuir al debate metodológico en torno a la medición de la procrastinación y la resiliencia académica. Al situar el análisis en el caso ecuatoriano, los resultados de la evaluación psicométrica de la Escala de Procrastinación Académica (EPA) y la Escala de Resiliencia Académica (ARS-30) permiten formular las siguientes conclusiones y reflexiones finales:

1. En el caso de la EPA, los análisis desarrollados arrojan resultados satisfactorios en cuanto a validez factorial, convergente, discriminante, consistencia interna y validez nomológica para el modelo bifactorial recortado. En otras palabras, la evaluación psicométrica efectuada sugiere que, para el caso ecuatoriano, los ítems de la EPA capturan a la procrastinación académica como un constructo bidimensional, y que la medición de dicha estructura factorial logra mayor calidad psicométrica cuando se emplea una versión recordada del instrumento. Así, se propone el uso de una EPA reducida de 12 ítems, compuesta de dos subescalas: autorregulación académica ( 9 ítems) y postergación de actividades ( 3 ítems). En consecuencia, los hallazgos descritos proporcionan evidencia confirmatoria para los resultados previamente obtenidos por Moreta-Herrera y DuránRodríguez (2018), a partir de datos de otra ciudad de Ecuador, Ambato.

2. En cuanto a la ARS-30, los resultados obtenidos indican validez factorial, convergente, discriminante y nomológica, además de buenos niveles de confiabilidad para el modelo trifactorial recortado con residuales correlacionados. En primer lugar, esto supone que un enfoque 
multidimensional resulta compatible para la aplicación de la ARS-30 en el caso ecuatoriano. Es decir, se corrobora que la versión adaptada de este instrumento conserva su capacidad de medir a la resiliencia académica como un constructo tridimensional, tal y como se propone originalmente por Cassidy (2016). Este resultado también confiere validez al proceso de traducción y adaptación de la ARS-30 al contexto cultural ecuatoriano. Al respecto, aunque se había mencionado que esta métrica no cuenta con antecedentes de adaptación y validación en países de la región, el reciente trabajo de adaptación al contexto español efectuado por Trigueros, Magaz-González, García-Tascón, Alias y Aguilar-Parra (2020) coincide al revelar una estructura factorial también tridimensional. Por lo tanto, en lo que respecta a contextos universitarios hispanoparlantes, la evidencia disponible apunta a que la resiliencia académica se manifiesta, según los ítems del ARS-30, como un constructo integrado por tres dimensiones o modalidades de respuesta adaptativa: perseverancia, reflexión y búsqueda adaptativa de ayuda, afectación negativa y respuesta emocional.

Por otra parte, el proceso de depuración de la ARS-30 condujo a la eliminación de 6 ítems $(1,5,6,15,23$ y 29). Cabe resaltar que el uso de intervalos de confianza derivados de un proceso de bootstrap o remuestreo permite introducir mayor confiabilidad a la hora de retener ítems, asegurando la permanencia de los indicadores que cuenten con cargas factoriales más estables. Como resultado, es razonable plantear que la versión recortada de la ARS-30 conserva los indicadores más robustos para la medición de cada subescala de resiliencia académica. Por último, se optó por introducir 2 correlaciones entre errores de medición, justificadas teóricamente por redundancia de contenido o vinculación conceptual entre ítems (Domínguez-Lara, 2019), de manera que no se trate de covarianzas exclusivas y localizadas únicamente en la muestra aquí estudiada, sino que puedan operar de manera más generalizada. No obstante, este ajuste requiere de mayor verificación a partir de nuevos estudios, con el fin de perfeccionar el esquema de utilización de este instrumento.

3. Los modelos de medición propuestos para la EPA y la ARS-30 constituyen instrumentos con propiedades psicométricas adecuadas para el estudio y la medición de la procrastinación y resiliencia académica en el entorno universitario ecuatoriano. Si bien nuevos estudios son necesarios para confirmar con mayor rigurosidad si los ajustes introducidos en estas métricas son correctos (principalmente con respecto a la ARS-30), los resultados de las pruebas realizadas sugieren que tales instrumentos tienen suficiente validez y confiabilidad para utilizarse en la práctica. Esta aplicabilidad no solo favorece a la investigación en torno a los constructos abordados, sino también a la formulación de intervenciones preventivas por parte de las universidades, que permitan contrarrestar problemas asociados con el desempeño y la permanencia del estudiantado a partir de la detección oportuna de perfiles desfavorables de resiliencia o procrastinación.

4. La validez factorial reportada, en cuanto a la estructura tridimensional de la ARS-30, sugiere implicaciones importantes para el debate teórico en torno a la conceptualización de la resiliencia académica, concretamente en lo que respecta a su clasificación. A diferencia de otros instrumentos que miden este constructo de manera actitudinal, mediante la autopercepción del accionar resiliente individual (Martin y Marsh, 2006); o predictiva, a partir de la presencia de factores protectores que favorecen resultados resilientes frente a situaciones académicas estresantes (Peralta-Díaz et al., 2006), la ARS-30 adopta un enfoque de proceso que se concentra en las respuestas adaptativas, de corte conductual, que el estudiantado puede desarrollar para lidiar con eventos adversos, lo cual refleja su capacidad de recuperación. En este sentido, la multidimensionalidad de la ARS-30 propone la existencia de al menos tres tipos de respuesta adaptativa, a través de las cuales se materializa la resiliencia académica. 
Estas modalidades de conducta resiliente coinciden con conceptos, factores y características que forman parte de la literatura disponible sobre resiliencia, aspecto que aporta validez teórica a la tipología planteada. Así, tanto la dimensión perseverancia como afectación negativa y respuesta emocional, se vinculan con el modelo 5-C elaborado por Martin y Marsh (2006), el cual reconoce 5 grandes factores explicativos de la resiliencia académica: confianza, compromiso, coordinación, control y compostura. Perseverancia, por su parte, se asocia con los factores compromiso y coordinación en aspectos como la formulación efectiva de objetivos, manejo de estrategias de estudio y persistencia ante las dificultades. Mientras que afectación negativa y respuesta emocional se relaciona con compostura, e involucra aspectos como evitar pensamientos y emociones negativas, concebir a los fallos como temporales y fuente de aprendizaje, limitar ideas catastrofistas, etc. Por otra parte, la dimensión reflexión y búsqueda adaptativa de ayuda conecta con el área conceptual de aprendizaje autorregulado y comprende cuestiones como la iniciativa y la búsqueda de ayuda en el profesorado, amistades o familia, la automotivación y el monitoreo del cumplimiento de metas (Newman, 2002). Igualmente, la reflexión sobre las propias fortalezas y debilidades constituye un proceso fundamental para la gestación de comportamientos resilientes, pues refiere a la negociación interna que la persona efectúa ante una situación demandante, confrontándose a sí misma para comprender mejor sus propias fuerzas, a fin de desarrollar cursos de acción efectivos para la resolución de problemas (De la Fuente et al., 2017). Cabe destacar, además, que las dimensiones identificadas con la ARS-30 contribuyen al entendimiento de la resiliencia académica en el contexto universitario, por lo que se debe verificar si las respuestas adaptativas analizadas se clasifican de forma similar en otros niveles educativos.

Con respecto a la bidimensionalidad constatada en la EPA, el factor postergación de actividades se ajusta de manera directa a la definición habitual de procrastinación académica. Mientras que el factor autorregulación académica engloba, de forma opuesta y con puntajes invertidos, reactivos centrados en el inicio oportuno de las actividades y tareas académicas, estableciendo una conexión con la teoría del aprendizaje autorregulado (Garzón-Umerenkova y Gil-Flores, 2017a). Según este enfoque, la procrastinación académica opera como un fallo autorregulatorio, por lo tanto, mayor capacidad autorregulatoria conduce a una mejor administración del tiempo, lo que implica menores niveles de procrastinación. No obstante, la formación de dicho factor puede tener una explicación más sencilla, siendo simplemente el resultado de ítems formulados en sentido inverso (Cassidy, 2015).

Dado el comportamiento multidimensional de la ARS-30, es recomendable que futuros trabajos profundicen en la comprensión de los tipos de comportamiento resiliente identificados, con el fin de explorar posibles diferencias en su modo de asociarse con otras variables de interés para la investigación educativa. Recomendación que también aplica para los estudios sobre procrastinación académica.

5. Entre las limitaciones del estudio se destaca el empleo de una muestra localizada en la ciudad de Quito - Ecuador, por lo que se recomienda que las próximas investigaciones sobre el tema empleen muestras representativas de alcance nacional. Del mismo modo, a nivel regional se requiere fortalecer el trabajo encaminado a la búsqueda de métricas más estandarizadas que puedan ser aplicables en una variedad de países. Las similitudes que la realidad universitaria ecuatoriana comparte con el resto de los países de América Latina sugieren la posibilidad de que las validaciones realizadas sean replicables a otros contextos regionales, lo cual deberá confirmarse por medio de análisis de invarianza cultural basados en muestras de dos o más países. 


\section{Referencias Bibliográficas}

Alegre, A. (2013). Autoeficacia y procrastinación académica en estudiantes universitarios de Lima Metropolitana. Propósitos y representaciones, 1(2), 57-82. doi: http://dx.doi.org/10.20511/pyr2013.v1n2.29

Allen, J., Robbins, S. B. y Sawyer, R. (2009). Can measuring psychosocial factors promote college success?. Applied Measurement in Education, 23(1), 1-22. doi: https://doi.org/10.1080/08957340903423503

Alonso-Aldana, R., Beltrán-Márquez, Y., Máfara-Duarte, R. y Gaytán-Martínez, Z. (2016). Relación entre rendimiento académico y resiliencia en una universidad tecnológica. Revista de Investigaciones Sociales, 2(4), 38-49. Recuperado de: https://www.ecorfan.org/republicofnicaragua/researchjournal/investigacionessociales/ journal/vol2num4/Revista_de_Investigaciones_Sociales_V2_N4.pdf\#page $=45$

Álvarez, Ó. (2010). Procrastinación general y académica en una muestra de estudiantes de secundaria de Lima metropolitana. Persona: Revista de la Facultad de Psicologia, (13), 159-177. Recuperado de: https://www.redal yc.org/pdf/1471/147118212009.pdf

Álvarez-Ramírez, L. Y. y Cáceres-Hernández, L. (2010). Resiliencia, rendimiento académico y variables sociodemográficas en estudiantes universitarios de Bucaramanga (Colombia). Psicología Iberoamericana, 18(2), 37-46. Recuperado de: https://www.redalyc.org/pdf/1339/133915921005.pdf

Arias-Gallegos, W. L. y Rivera, R. (2018). Análisis psicométrico de una escala de procrastinación académica en estudiantes de Psicología de una universidad privada de Arequipa. Educationis Momentum, 4(1), 5-24. Recuperado de https://bit.ly/3hqJk0x

Ato, M., López-García, J. J., y Benavente, A. (2013). A classification system for research designs in psychology. Anales De Psicologia / Annals of Psychology, 29(3), 1038-1059. doi: https://doi.org/10.6018/analesps.29.3.178511

Batista-Foguet, J. M., Coenders, G. y Alonso, J. (2004). Análisis factorial confirmatorio. Su utilidad en la validación de cuestionarios relacionados con la salud. Medicina clínica, 122(1), 21-27. Recuperado de https://medes.com /publication/12004

Barraza-Macías, A. y Barraza-Nevárez, S. (2018). Evidencias de validez y confiabilidad de la escala de procrastinación académica en una población estudiantil mexicana. Revista depsicología y ciencias del comportamiento de la Unidad Académica de Ciencias Jurídicas y Sociales, 9(1), 75-99. Recuperado de http://www.scielo.org.mx/pdf/rpcc/v9n 1/2007-1833-rpcc-9-01-75.pdf

Bethencourt-Benítez, J. T., Cabrera-Pérez, L., Hernández-Cabrera, J. A., Álvarez-Pérez, P. y González-Afonso, M. (2017). Variables psicológicas y educativas en el abandono universitario. ElectronicJournal of Research in Education Psychology, 6(16), 603-622. doi: http://dx.doi.org/10.25115/ejrep.v6i16.1298

Bollen, K. A. (1989). Structural equations with latent variables. Toronto, Canadá: A Wiley-Interscience Publication

Bravo, F., Illescas, L., Larriva, S. y Peña, M. (2017). Causas de Deserción en el Ingreso a la Universidad; un Estudio de Caso. Revista de la Facultad de Ciencias Quimicas, (18), 48-59. Recuperado de https://publicaciones.ucuenca.e du.ec/ojs/index.php/quimica/article/view/1693

Busko, D. A. (1998). Causes and consequences of perfectionism and procrastination: A structural equation model (Tesis de maestría no publicada). University of Guelph, Ontario, Canadá.

Byrne, B. M. (2010): Structural equation modeling with AMOS: Basic concepts, applications, and programming. New York, United States: Routledge.

Caldera-Montes, J. F., Aceves-Lupercio, B. I. y Reynoso-González, Ó. U. (2016). Resiliencia en estudiantes universitarios. Un estudio comparado entre carreras. Psicogente, 19(36), 227-239. doi: http://dx.doi.org/10.17 081/psico.19.36.1294

Cassidy, S. (2016). The Academic Resilience Scale (ARS-30): a new multidimensional construct measure. Frontiers in psychology, 7, 1787. Recuperado de https://www.ncbi.nlm.nih.gov/pmc/articles/PMC5114237/

Cassidy, S. (2015). Resilience building in students: the role of academic self-efficacy. Frontiers in psychology, 6, 1781. doi https://doi.org/10.3389/fpsyg.2015.01781 
Corchado-Castillo, A. I., Díaz-Aguado, M. J. y Martínez-Arias, R. (2017). Resiliencia en adolescentes expuestos a condiciones vitales de riesgo. Cuadernos de trabajo social, 30(2), 477-486. doi: https://doi.org/10.5209/CUT S. 54357

De la Fuente, J., Fernández-Cabezas, M., Cambil, M., Vera, M. M., González-Torres, M. C. y Artuch-Garde, R. (2017). Linear relationship between resilience, learning approaches, and coping strategies to predict achievement in undergraduate students. Frontiers in psychology, 8, 1039. doi: https://doi.org/10.3389/fpsyg.2017.01039

Díaz-Peralta, C. (2008). Modelo conceptual para la deserción estudiantil universitaria chilena. Estudios pedagógicos (Valdivia), 34(2), 65-86. doi: http://dx.doi.org/10.4067/S0718-07052008000200004

Domínguez-Lara, S. (2017). Procrastinación académica, afrontamiento de la ansiedad pre-examen y rendimiento académico en estudiantes de psicología: análisis preliminar. Cultura: Revista de la Asociación de Docentes de la USMP, 31, 181-193. doi: https://doi.org/10.24265/cultura.2017.v31.10

Domínguez-Lara, S. (2019). Correlación entre residuales en análisis factorial confirmatorio: una breve guía para su uso e interpretación. Interacciones, 5(3), e207. doi: https://doi.org/10.24016/2019.v5n3.207

Domínguez-Lara, S., Villegas-García, G. y Centeno-Leyva, S. (2014). Procrastinación académica: validación de una escala en una muestra de estudiantes de una universidad privada. Liberabit, 20(2), 293-304. Recuperado de htt p://www.scielo.org.pe/pdf/liber/v20n2/a10v20n2.pdf

Farrington, C.A., Roderick, M., Allensworth, E., Nagaoka, J., Keyes, T.S., Johnson, D.W. y Beechum, N.O. (2012). Teaching adolescents to become learners. The role of noncognitive factors in shaping school performance: A critical literature review. Chicago, United States: University of Chicago Consortium on Chicago School Research.

Ferreyra, M. M. (2017). The Demand Side of the Higher Education Expansion. En M. M. Ferreyra, C. Avitabile, J. Botero-Álvarez, F. Haimovich-Paz y S. Urzúa (Eds.), At a Crossroads: Higher Education in Latin America and the Caribbean (pp. 47-76). Washington DC, United States: World Bank.

Ferreyra, M. M., Avitabile, C., Botero Álvarez, J., Haimovich-Paz, F. y Urzúa, S. (2017). Momento decisivo: La educación superior en América Latina y el Caribe. Washington DC, Estados Unidos: Banco Mundial.

Field, A. (2013). Discovering Statistics Using IBM SPSS Statistics. London, England: Sage.

Friedland, N. (2005). Introduction-The "elusive" concept of social resilience. En N. Friedland, A. Arian, A. Kirschnbaum, A. Karin y N. Fleischer (Eds.), The Concept of Social Resilience (pp. 7-10). Haifa, Israel: The Technion Samuel Neaman Institute.

Garzón-Umerenkova, A. y Gil-Flores, J. (2017a). El papel de la procrastinación académica como factor de la deserción universitaria. Revista Complutense de Educación, 28(1), 307-324. https://doi.org/10.5209/rev_RCED.2017.v2 8.n 1.49682

Garzón-Umerenkova, A. y Gil-Flores, J. (2017b). Procrastinación académica en el alumnado universitario no tradicional. Electronic Journal of Research in Education Psychology, 15(43), 510-532. doi: http://dx.doi.org/10. 25115/ejrep.43.16134

González-Torres, M. C. y Artuch-Garde, R. (2017). Perfiles de resiliencia y estrategias de afrontamiento en la universidad: variables contextuales y demográficas. Electronic Journal of Research in Education Psychology, 12(34), 621-648. doi: http://dx.doi.org/10.25115/ejrep.34.14032

Guzmán-Valenzuela, C. (2017). Tendencias globales en Educación Superior y su impacto en América Latina: desafíos pendientes. Lenguas Modernas, (50), 15-32. Recuperado de: https://analesfcfm.uchile.cl/index.php/LM/articl e/view/49248

Hagger, M. S., Gucciardi, D. F. y Chatzisarantis, N. L. (2017). On nomological validity and auxiliary assumptions: The importance of simultaneously testing effects in social cognitive theories applied to health behavior and some guidelines. Frontiers in psychology, 8, 1933. doi: https://doi.org/10.3389/fpsyg.2017.01933

Kim, K. R. y Seo, E. H. (2015). The relationship between procrastination and academic performance: A meta-analysis. Personality and Individual Differences, 82, 26-33. doi: https://doi.org/10.1016/j.paid.2015.02.038

López-Segrera, F. (2016). Educación superior comparada: tendencias mundiales y de América Latina y Caribe. Avaliação: Revista da Avaliação da Educação Superior (Campinas), 21(1), 13-32. doi: http://dx.doi.org/10.159 0/S1414-40772016000100002 
Martin, A. (2002). Motivation and academic resilience: Developing a model for student enhancement. Australian journal of education, 46(1), 34-49. doi: https://doi.org/10.1177/000494410204600104

Martin, A. J. y Marsh, H. W. (2006). Academic resilience and its psychological and educational correlates: A construct validity approach. Psychology in the Schools, 43(3), 267-281. doi: https://doi.org/10.1002/pits.20149

Moreta-Herrera, R. y Durán-Rodríguez, T. (2018). Propiedades psicométricas de la Escala de Procrastinación Académica (EPA) en estudiantes de psicología de Ambato, Ecuador. Salud \& Sociedad, 9(3), 236-247. doi: htt ps://doi.org/10.22199/S07187475.2018.0003.00003

Munizaga, F., Cifuentes, M. B. y Beltrán, A. (2018). Retención y Abandono Estudiantil en la Educación Superior Universitaria en América Latina y el Caribe: Una Revisión Sistemática. Education Policy Analysis Archives, 26(61), 1-36. doi: http://dx.doi.org/10.14507/epaa.26.3348

Narayanan, S. S. y Weng Onn, A. C. (2016). The Influence of Perceived Social Support and Self-Efficacy on Resilience among first year Malaysian students. Kajian Malaysia, 34(2), 1-23. doi: http://dx.doi.org/10.21315/km2016. 34.2 .1

Newman, R. S. (2002). How self-regulated learners cope with academic difficulty: The role of adaptive help seeking. Theory into practice, 41(2), 132-138. doi: https://doi.org/10.1207/s15430421tip4102_10

Peralta-Díaz, S. C., Ramírez-Giraldo, A. F. y Castaño-Buitrago, H. (2011). Factores resilientes asociados al rendimiento académico en estudiantes pertenecientes a la Universidad de Sucre (Colombia). Psicología desde el Caribe, (17), 196-219. Recuperado de: https://www.redalyc.org/pdf/213/21301709.pdf

Ponce, J. y Carrasco, F. (2016). Acceso y equidad a la educación superior y posgrado en el Ecuador, un enfoque descriptivo. Mundos Plurales - Revista Latinoamericana de Politicas y Acción Pública, 3(2), 9-22. doi: https://d oi.org/10.17141/mundosplurales.2.2016.2841

Rama, C. (2009). La tendencia a la masificación de la cobertura de la educación superior en América Latina. Revista iberoamericana de educación, (50), 173-195. Recuperado de: https://core.ac.uk/download/pdf/41563563.pdf

Ramada-Rodilla, J. M., Serra-Pujadas, C. y Delclós-Clanchet, G. L. (2013). Adaptación cultural y validación de cuestionarios de salud: revisión y recomendaciones metodológicas. Salud pública de México, 55(1), 57-66. Recuperado de: http://www.scielo.org.mx/pdf/spm/v55n1/v55n1a09.pdf

Richardson, M., Abraham, C. y Bond, R. (2012). Psychological correlates of university students' academic performance: a systematic review and meta-analysis. Psychological bulletin, 138(2), 353. doi: https://doi.org/1 $0.1037 / \mathrm{a} 0026838$

Schermelleh-Engel, K., Moosbrugger, H. y Müller, H. (2003). Evaluating the fit of structural equation models: Tests of significance and descriptive goodness-of-fit measures. Methods of psychological research online, 8(2), 23-74. Recuperado de https://psycnet.apa.org/record/2003-08119-003

Steel, P., y Klingsieck, K. B. (2016). Academic procrastination: Psychological antecedents revisited. Australian Psychologist, 51(1), 36-46. doi: https://doi.org/10.1111/ap.12173

Trigueros, R., Magaz-González, A. M., García-Tascón, M., Alias, A. y Aguilar-Parra, J. M. (2020). Validation and Adaptation of the Academic-Resilience Scale in the Spanish Context. International Journal of Environmental Research and Public Health, 17(11), 3779. doi: https://doi.org/10.3390/ijerph17113779

Van Eerde, W. (2003). A meta-analytically derived nomological network of procrastination. Personality and individual differences, 35(6), 1401-1418. doi: https://doi.org/10.1016/S0191-8869(02)00358-6

Vizoso-Gómez, C. M. y Arias-Gundín, O. (2018). Resiliencia, optimismo y burnout académico en estudiantes universitarios. European Journal of Education and Psychology, 11(1), 47-59. doi: https://doi.org/10.30552/eje p.v11i1.185

Werner, C. y Schermelleh-Engel, K. (2010). Deciding between competing models: Chi-square difference tests. Goethe University. Recuperado de: https://perma.cc/2RTR-8XPZ

Zumárraga-Espinosa, M. (2020). Aportes metodológicos para la medición del sentido de eficacia politica: Evidencia empírica de Quito-Ecuador. Empiria: Revista de metodología de ciencias sociales, (45), 113-142. doi: https://do i.org/10.5944/empiria.45.2020.26306 